\title{
ВОЕННЫЕ ПРЕСТУПЛЕНИЯ И ПРЕСТУПЛЕНИЯ ПРОТИВ ЧЕЛОВЕЧНОСТИ: ОБЩЕЕ И ОСОБЕННОЕ В РЕШЕНИЯХ МЕЖДУНАРОДНЫХ УГОЛОВНЫХ ТРИБУНАЛОВ АD НОС
}

Авторы подчеркивают, что для отечественной уголовно-правовой системы имеют силу решения международных уголовных трибуналов по Руанде и бывшей Югославии. Это особенно важно, так как именно в них дано официальное разъяснение сущности военных преступлений и преступлений против человечности. Однако в решениях международных трибуналов ad hoc сходные по объективным и субъективным признакам деяния (убийства, пытки, акты сексуального насилия и другие) квалифицировались в одних случаях в качестве военных преступлений, а в других - как преступления против человечности.

В соответствии с действующими конвенционными нормами, совершение актов насилия в отношении военнопленных и приравненных к ним лиц, а также в отношении пленных в ходе внутренних вооруженных конфликтов должно расцениваться как военное преступление. Поэтому основная проблема при квалификации содеянного как преступления против человечности или военного преступления возникает только в случае, если потерпевшими являются представители гражданского населения.

Исходя из предписаний норм международного уголовного права и решений международных трибуналов ad hoc, если преступное деяние (при установлении всех «конвенционных» и «контекстуальных» условий) совершено в отношении представителей гражданского населения в ходе вооруженного конфликта междуна- родного или немеждународного характера либо в непосредственной связи с таким конфликтом, то оно должно быть квалифицировано как военное преступление.

В соответствии с конвенциональными нормами и общими нормами международного права, для квалификации содеянного как преступления против человечности должен быть установлен контекст «широкомасштабного» и/или «систематического» нападения на гражданское население. Принципиально важна позиция Международного трибунала по бывшей Югославии, о том, что нападение на гражданское население не обязательно должно одновременно являться и широкомасштабными, и систематическими. Данное деяние может быть квалифицировано как преступление против человечности, если соответствует хотя бы одному из этих «контекстуальных" условий.

В решениях международных трибуналов ad hoc выработано еще одно принципиально важное для квалификации преступлений против человечности правило: вовлеченность государства в совершение преступлений против человечности (в виде осуществления «плана» или «политики») не является обязательным признаком.

Ключевые слова: военные преступления, преступления против человечности, Нюрнбергский трибунал, Римский Статут Международного уголовного суда, Международный трибунал по бывшей Югославии, Международный трибунал по Руанде.

\section{WAR CRIMES AND CRIMES AGAINST HUMANITY: GENERAL AND PARTICULAR IN THE DECISIONS OF INTERNATIONAL CRIMINAL TRIBUNALS AD HOC}

The authors underline that the decisions of international criminal tribunals in Rwanda and the former Yugoslavia are valid for the domestic criminal law system. This is especially important; since it is in them that an official explanation of the essence of war crimes and crimes against humanity is given. However, in decisions of international ad hoc tribunals, acts that were similar in objective and subjective terms (murder, torture, acts of sexual violence and others) were qualified in some cases as war crimes, and in others as crimes against humanity.

In accordance with applicable convention norms, the commission of acts of violence against prisoners of war and persons equated with them, as well as against prisoners during internal armed conflicts, should be regarded as a war crime. Therefore, the main problem in qualifying an offense as a crime against humanity or a war crime arises only if the victims are civilians.
Based on the requirements of international criminal law and the decisions of international ad hoc tribunals, if a criminal act (when all (cconventional) and "contextual») conditions are established) was committed against representatives of the civilian population during an armed conflict of international or non-international character or in direct connection with such conflict, it must be qualified as a war crime.

In accordance with conventional norms and general norms of international law, in order to qualify an offense as a crime against humanity, the context of «widespread» and/ or «systematic» attacks on the civilian population must be established. The position of the International Tribunal for the Former Yugoslavia that the attack on the civilian population does not have to be both large-scale and systematic is fundamentally important. This act can be qualified as a crime against humanity if it meets at least one of these «contextual») conditions. 
In the decisions of the international ad hoc tribunals, one more principle has been developed for qualifying crimes against humanity: the involvement of the state in committing crimes against humanity (in the form of implementing a "plan» or "policy») is not a mandatory feature.

В решениях международных трибуналов по итогам Второй Мировой войны (приговоры Нюрнбергского и Токийского трибуналов), ставших фундаментальной основой для всей современной системы международного уголовного права, в качестве наиболее тяжких преступлений против мира и безопасности всего человечества были расценены преступление агрессии (агрессивной войны), военные преступления и преступления против человечности. Во второй половине $X X$ века перечень военных преступлений был значительно расширен четырьмя Женевскими конвенциями о защите жертв войны 1949 г. и двумя Дополнительными протоколами к этим конвенциям 1977 г. (при этом особо надо подчеркнуть, что II Дополнительный протокол признал юридическую возможность совершения военных преступлений в вооруженных конфлликтах немеждународного характера). Определенную роль в конвенциональном определении системы военных преступлений сыграли и иные акты международного права, регламентирующие правила ведения вооруженных конфрликтов (в частности, Конвенция о запрещении военного или любого иного враждебного использования средств воздействия на природную среду 1977 г., Конвенция о запрещении или ограничении применения конкретных видов оружия, которые могут считаться наносящими чрезмерные повреждения или имеющими неизбирательное действие 1981 г.).

Что касается определения системы преступлений против человечности, то, вплоть до конца XX века, она, по существу, оставалась в рамках, определенных Уставом Нюрнбергского трибуна. Наиболее существенным стало выделение геноцида в качестве наиболее тяжкого преступления против безопасности человечества (человечности), сделанное Конвенцией о предупреждении преступления геноцида и наказании за него 1948 г., а также признание апартеида самостоятельным преступлением против человечности в силу принятия в 1973 г. Международной конвенции о пресечении преступления апартеида и наказании за него.

В конце XX века ввиду трагических событий в Руанде и бывшей Югославии решениями Совета Безопасности ООН были учреждены специальные уголовные трибуналы ad hoc. Данные трибуналы на протяжении более чем двадцати лет рассматривали дела о военных преступлениях и преступлениях против человечности (а также об актах геноцида) в соответствии с правилами юрисдикции, установленными в ст. 2-5 Устава Международного трибунала по бывшей Югославии (далее - МТБЮ) и в ст. 2-3 Устава Международного трибунала по Руанде (далее - МТP).
Key words: war crimes, crimes against humanity, Nuremberg Tribunal, Rome Statute of the International Criminal Court, International Tribunal for the Former Yugoslavia, International Tribunal for Rwanda

Одним из наиболее «знаковых» событий в плане развития международного уголовного права и учреждения постоянно действующего органа международной уголовной юстиции стало принятие в 1998 году Римского Статута Международного уголовного суда, вступившего в силу в 2002 г Именно в этом документе в наиболее «завершенном» виде в настоящее время сформулирован перечень военных преступлений и преступлений против человечности (ст. 7 и 8). В силу целого ряда обстоятельств данный документ не имеет для нашего государства юридической силы, так как Российская Федерация де-факто отозвала свою подпись под ним в соответствии с распоряжением Президента РФ от 16 ноября 2016 г № 361-рп.

Тем не менее, для отечественной уголовно-правовой системы имеют силу все решения международных трибуналов ad hoc по Руанде и бывшей Югославии, чья юрисдикция признается Российской Федерацией. Как подчеркивается в доктрине, это обстоятельство “особенно важно», так как именно в них дано «официальное разъяснение» сущности, элементов и конкретных признаков военных преступлений и преступлений против человечности, «применимое к положениям национального уголовного законодательства» [2, c. 451-452; 3, c. 147-148].

Необходимо отметить, что в доктрине высказаны различные, порой, взаимоисключающие позиции по отношению к политическим аспектам и «наследию» деятельности этих органов международного правосудия. Тем не менее, подавляющее большинство отечественных и иностранных авторов единодушны в том, Что в решениях МТБЮ и МТР накоплен большой опыт применения материальных норм международного уголовного права (некоторые авторы говорят даже о «прецедентном праве» или о «прецедентном наследии» деятельности международных трибуналов ad hoc. Именно этот опыт может и должен быть использован при применении соответствующих норм национального уголовного законодательства о военных преступлениях и преступлениях против человечности $[2$ с с. $278-279 ; 4$ с с. $10-14$; 5 , c. 45-47].

Несмотря на существенную разницу в перечне деяний, считающихся военными преступлениями или преступлениями против человечности, необходимо обратить внимание на то обстоятельство, что де-факто одно и то же деяние может одновременно подпадать под признаки того или иного военного преступления и преступления против человечности. Это касается, например: убийств, пыток, умышленного причинения «серьезного» вреда здоровью, актов сексуального насилия. По- 
этому возникает закономерный вопрос: как правильно квалифицировать такое деяние?

Обратимся к «наследию» международных уголовных трибуналов ad hoc.

В деятельности МТЕЮ глубоко изучены объективные и субъективные признаки, прежде всего военных преступлений. В частности, в решениях по делам Prosecutor v. Z. Aleksovsky, Prosecutor v. $T$ Blaškič, Prosecutor v. Z. Delalič, Z. Mučič , H. Delič E. Landzo, Prosecutor v. A. Furundzija, Prosecutor v. R. Krstič, Prosecutor v. D. Kunarač, Prosecutor v Z. Mučič, Prosecutor v. D. Tadič дано официальное толкование признакам таких военных преступлений, совершаемых в отношении участников оппозиционных вооруженных сил и/или гражданских лиц, как: 1) убийство [21, § 439]; 2) пытка в отношении плененных участников вооруженных групп и/или представителей гражданского населения $[10, \S 468 ; 18, \S 182] ; 3)$ «жестокое (дурное) обращение» [10, § 1086, 1124]; 4) умышленное причинение "серьезных телесных повреждений» или "ущерба» здоровью, включая «ментальный» (психический) вред [10, § 509; 17, § 513]; 5) акты сексуального насилия $[7, \S \S 158,173 ; 13$, § 164172].

За время деятельности органов международной уголовной юстиции ad hoc в решениях MTP (в частности, по делам Prosecutor v. J.-P. Akayesu; Prosecutor v. I. Bagilishema; Prosecutor v. S. Gacumbitsi; Prosecutor v. C. Kayishema and O. Ruzindana; Prosecutor v. E. Ntakirutimana and G. Ntakirutimana; Prosecutor v. G. Rutaganda) и МТБЮ (например, по делам Prosecutor v. D. Kordič and M. Cerkez; Prosecutor v. R. Krstičc; Prosecutor v. M. Kvocka et al; Prosecutor v. M. Milutinovic;; Prosecutor v. M. Stakič) многократно давалось содержательное толкование таким преступлениям против человечности, совершенным против представителей гражданского населения в контексте «широкомасштабного или систематического нападения», как: 1) убийство [8, § 88-89; 11, § 309 $16, \S 37 ; 20, \S 261 ; 22 \S 138] ; 2)$ "истребление» $[8, \S 90 ; 11, \S 309 ; 14 \S 146-147 ; 17, \S 503 ; 24$ $\S 516 ; 25$ § 84; 26, § 260]; 3) пытка [6, § 594-596; $13, \S 267 ; 18, \S 482 ; 21 \S 496]$;) акты сексуального насилия [6, § 598; 13 § 185; 18, § 458].

Таким образом, в решениях МТР и МТБЮ сходные по объективным и субъективным признакам деяния квалифицировались в одних случаях в качестве преступлений против человечности, а в других - как военные преступления. Однако, как известно, в силу принципа международного уголовного права «не суди дважды» (ne bes in idem) имеющего прямые аналоги в национальном уголовном законодательстве (например, в ст. 6 УК РФ), одно деяние не может быть одновременно квалифицировано либо как преступление против человечности, либо как военное преступление. В связи с этим возникает проблема правильной квалификации указанных деяний в качестве военного преступления или преступления против человечности.

Представляется, что для верной квалификации необходимо использовать, с одной стороны, предписания действующих норм международного уголовного права, а, с другой - «контекстуальные» и «квалификационные» правила, выработанные в решениях самих международных уголовных трибуналов ad hoc.

1. В соответствии с уставами МТР и МТБЮ, а также конвенционными нормами (в частности, предписаниями Женевских конвенций о защите жертв войны 1949 г. и Дополнительных протоколов к ним 1977 г.), «адресатами» военных преступлений являются: 1) военнопленные и приравненные к ним лица в международном вооруженном конфликте; 2) пленные в ходе внутренних вооруженных конфликтов; 3) гражданское население, ставшее объектом преступных посягательств в ходе вооруженных конфликтов международного и внутреннего характера.

Потерпевшими от преступлений против человечности конвенционные нормы и общие нормы международного права называют только представителей гражданского населения. Поэтому совершение убийств, актов «жестокого обращения», действий, расцениваемых как сексуальное насилие и прочих преступных деяний в отношении военнопленных и приравненных к ним лиц, а также в отношении пленных в ходе внутренних вооруженных конфликтов должно расцениваться как военное преступление.

Следовательно, основная проблема при квалификации совершенного деяния как преступления против человечности или военного преступления возникает только в случае, если потерпевшими являются представители гражданского населения.

2. Исходя из предписаний норм международного уголовного права и решений международных трибуналов ad hoc, практически все авторы единодушны в том, что для квалификации содеянного как военного преступления необходимо установить «контекстуальную связь» совершенного деяния с вооруженным конфликтом. Cогласно решению по делу Prosecutor v. D. Kordic and M. Čerkez, любое, даже "самое страшное», "общеуголовное» преступление может быть квалифицировано в качестве военного преступления только в случае установления «очевидной связи» совершенного преступления с фрактически существующим вооруженным конфликтом $[15, \S 22]$.

При этом, как отмечается в решениях МТБЮ, достаточно установить, что «инкриминируемые преступления были близко связаны с военными действиями, происходящими в других частях территорий, контролируемых сторонами конфликта». Согласно решениям по делам Prosecutor $v$. D. Kunarač et al и Prosecutor v. D. Tadič, военное преступление не обязательно совершается на непосредственно территории идущего вооруженного конфликта: вполне допускается ситуация, когда такое преступление может быть совершено вне непосредственной территории вооруженного конфрликта, но в обязательной связи с вооруженным конфликтом $[18, \S 57 ; 27, \S 70]$. Как подчеркивает А. Г. Кибальник, «одним из наиболее известных решений Международного трибунала по 
бывшей Югославии стало признание виновными в военных преступлениях группы боснийских мусульман, совершивших убийства, пытки и иные массовые акты насилия в отношении заключенных-сербов в концентрационном лагере "Челебичи"” [2, с. 440-441]. В судебном решении по делу Prosecutor v. Z. Delalič, Z. Mučič, H. Delič, $E$. Landzo сказано, расправа над сербскими пленными в этом лагере имела место, когда на этой территории вооруженный конфликт уже не шел. Однако виновные «были арестованы и задержаны в результате военных действий, проводимых от имени правительства Боснии и Герцеговины и в ходе вооруженного конфликта, стороной которого являлась последняя» $[10, \S 196]$.

Наконец, в решениях международных уголовных трибуналов ad hoc принципиально важным моментом стало указание на тот фракт, что военные преступления в равной степени могут совершаться в ходе международного и немеждународного (внутреннего) вооруженного конфликта. Например, в принципиально важном решении по делу Prosecutor v. D. Tadič указано, что качестве именно военного преступления необходимо расценивать «серьезные нарушения как общей [для Женевских конвенций] Статьи 3 и дополняющих ее других общих принципов и норм защиты жертв внутреннего вооруженного конфликта, так и за серьезные нарушения определенных фундаментальных принципов и норм, касающихся средств и методов ведения войны в ходе гражданских волнений» [27, § 128].

Таким образом, исходя из смысла решений МТБЮ, если преступное деяние (при установлении всех "конвенционных» и "контекстуальных" условий и признаков) совершено в отношении представителей гражданского населения в ходе вооруженного конфликта международного или немеждународного характера либо в непосредственной связи с таким конфликтом, то оно должно квалифицироваться в качестве военного преступления. Говоря иными словами, несмотря на совпадение объективной стороны многих преступлений против человечности и военных преступлений, для квалисрикации содеянного как преступления против человечности необходимо исключить его непосредственную связь с вооруженным конфоликтом (как международным, так и внутренним)

Надо отметить, что в Приговоре Нюрнбергского трибунала указывалось, что преступления против человечности непосредственно связаны с военными действиями (вооруженным конфликтом). Однако в настоящее время практика международных трибуналов ad hoc (прежде всего, МТЕЮ) сфформировала принципиально иной подход. Например, в одном из «знаковых» решений МТБЮ по делу Prosecutor v. D. Tadič сказано о том, что «преступления против человечества не требуют связи с международным вооруженным конфликтом». Соответственно, в настоящее время «нет ни логического, ни правового основания для этого требования» - то есть для требования обязательной увязки совершения преступления против человечности с вооруженным конфоликтом или в его контексте [27, § 140-142].

3. В соответствии с конвенциональными нормами и общими нормами международного права, для квалификации содеянного как преступления против человечности должен быть установлен контекст "иирокомаситабного» и/или «систематического» нападения на гражданское население.

Прежде всего, в решениях международных уголовных трибуналов ad hoc отмечено, что именно «широкий масштаб) и «систематичность» нападений на гражданское население «трансформируют обычное преступление, наказуемое по внутригосударственному праву, в преступление против человечности, которое ... стало затрагивать также и интересы международного права» [28, § 644]. Принципиально важна позиция, выработанная в решениях МТБЮ, о Том, что нападения, совершаемые на гражданское население, не обязательно должны одновременно обладать признаками «широкомасштабности» и “систематичности». Такие нападения, в соответствии в решением по делу Prosecutor v. M. Naletillič and V. Martinovič, квалифицируются в качестве преступления против человечности при «соответствии» хотя бы одному из этих «контекстуальных условий » $[23, \S 26]$.

В решениях международных уголовных трибуналов ad hoc указывается, что под «широкомасштабным нападением», как правило, понимается то обстоятельство, что нападение имеет «крупные масштабы» и направлено «против значительного числа жертв". В свою очередь, как справедливо указывает А. Кассезе, «систематический» характер нападений на гражданское население подразумевает, что «насильственные действия», как правило, предполагают методичные и организованные действия и совершаются (в рамках составленного заранее плана» либо в целом «проводимой политики» со стороны государства или какой-либо организации [4, с. 92-95].

Эта позиция подтверждается практикой международных уголовных трибуналов ad hoc. Например, в решении Prosecutor v. G. Jelisic̈ говорится, что «существование признанной политики, направленной против определенного сообщества, учреждение параллельных институтов, предназначенных для реализации этой политики, участие высокого уровня политических или военных чиновников, вовлеченность значительных финансовых, военных или других ресурсов, а также масштаб или повторяемый, неизменный и непрерывный характер насилия, совершенного против определенного гражданского населения, находятся среди факторов, которые могут продемонстрировать широкомасштабную или систематическую природу нападения» [12, § 53]. Данное правило подтвержденов других решенияхМТБЮнапример, в решениях по делам Prosecutor $v$. $D$. Kordič and $M$. Čerkez $u$ Prosecutor v. D. Kunarač et al $[15, \S 178 ; 19, \S 103]$ 
Как отмечено в литературе, в решениях МТР систематичный характер нападений на гражданское население определен как совершение таких нападений в качестве «организованных по регулярному образцу на основе общей политики вовлекающих существенные общественные или частные ресурсы» [3, с. 149-150]. В частности, в решении по делу Prosecutor v. J.-P. Akayesu выработано очень важное квалификационное правило о том, что для признания указанных нападений в качестве преступлений против человечности «не требуется, чтобы эта политика [т.е. практика совершения широкомасштабных и/или систематичных нападений на гражданское население] была принята фрормально как политика государства» $[6, \S 580]$.

Исходя из практики МТР и МТБЮ, можно говорить, что в решениях международных трибуналов ad hoc выработано еще одно принципиально важное для квалификации преступлений против человечности правило: вовлеченность государства в совершение преступлений против человечности (в виде осуществления «плана» или «политики») не является обязательным, «квалифрикационным» признаком преступления против человечности. С другой стороны, согласно решению по делу Prosecutor V. T. Blaškič, установление такой (вовлеченности) «может быть важным при доказывании того, что нападение было направлено против гражданского населения и что оно было широкомасштабным или систематическим» [9, $\S 120]$. Данное правило получило положительную оценку в отечественной и западной доктрине международного уголовного права [3, с. $151 ; 4$, с. 96]

С точки зрения субъективной стороны (mens rea), лицо, совершающее преступление против человечности, как правило, действует «намеренно» (в российском уголовном праве к «намеренности» наиболее близка конструкция прямого умысла). Согласно решениям международных уголовных трибуналов ad hoc, такое лицо «стремится причинить вред" представителям гражданского населения. Однако международное правосудие допускает и «безрассудно безразличное» отношение к причинению вреда представителям гражданского населения в результате совершенных нападений. Согласно решениям по делам Prosecutor v. C. Kayishema and O. Ruzindana u Prosecutor v. D. Kunarac̆ et al, в этом случае достаточно установить, что виновное лицо осознавало (должно было осознавать), что «совершает действия в рамках широкомасштабного и/или систематического нападения» $[14, \S 133-134 ; 18$, § 410]

Общий вывод. В силу того, что многие военные преступления и преступления против человечности имеют много общих признаков вплоть до их «смешения», в конвенционных нормах международного уголовного права и решениях международных уголовных трибуналов ad hoc выработаны критерии их отграничения. По существу, квалификация содеянного как преступления против человечности должна проводиться по «остаточному правилу".

Во-первых, в отличие от военных преступлений, потерпевшими от преступлений против человечности могут признаваться лишь представители гражданского населения. Во-вторых, должен быть исключен “контекст связанности» совершенного деяния с вооруженным конфликтом международного или внутреннего характера. В-третьих, для квалификации нападений на представителей гражданского населения как преступлений против человечности необходимо установить «контексты» их «широкомасштабности» и/или «систематичности» как они определены в решениях международных уголовных трибуналов ad hoc.

\section{Литература}

1. Кибальник А. Г. Куда идет международная уголовная юстиция? // Всероссийский криминологический журнал. 2018. T.12. №2. С. 300-310.

2. Кибальник А. Г. Понимание военных преступлений в решениях современных международных трибуналов // Российский ежегодник уголовного права. №7. СПб: Юридическая книга, 2013. С. 439-453.

3. Кибальник А. Г. Преступления против человечности в решениях современных международных судов (трибуналов) // Библиотека уголовного права и криминологии. 2015. №4. С.147-159.

4. Cassese A., Gaeta P., Baig L., Fan M., Gosnell C., Whiting A. Cassese's International Criminal Law. 3rd ed. Oxford University Press, 2013. 414 p.

5. Kittichaisaree K. International Criminal Law. Oxford University Press, 2001. 482 p.

6. Prosecutor v. J.-P. Akayesu. Case № ICTR-96-4-T. 2 September 1998.

7. Prosecutor v. Z. Aleksovsky. Case № IT-95-14/1- T. 25 June 1999.

8. Prosecutor v. I. Bagilishema. Case № ICTR-95-1A-T. 7 June 2001

9. Prosecutor v. T. Blaškič. Case № IT-95-14-A. 29 July 2004.

10. Prosecutor v. Z. Delalič, Z. Mučič, H. Delič, E. Landzo. Case № IT-96-21-T. 16 November 1998

11. Prosecutor v. S. Gacumbitsi. Case № ICTR-2001-64-T. 17 June 2004.

12. Prosecutor v. G. Jelisič. Case № IT-95-10-T. 14 December 1999.

13. Prosecutor v. A. Furundzija. Case № IT-95-17/1-T. 10 December 1998

14. Prosecutor v. C. Kayishema and O. Ruzindana. Case № ICTR-95-1-T. 21 May 1999.

15. Prosecutor v. D. Kordič and M. Čerkez. Case № IT-95-1 4/2-T. 26 February 2001.

16. Prosecutor v. D. Kordič and M. Čerkez. Case № IT-95-14/2-A. 17 December 2004.

17. Prosecutor v. R. Krstič. Case № IT-98-33-T. 2 August 2001

18. Prosecutor v. D. Kunarač et al. Case № IT-96-23/23/1-T. 22 February 2001.

19. Prosecutor v. D. Kunarač et al. Case № IT-96-23/23/1-A. 12 June 2002. 
20. Prosecutor v. M. Kvočka et al. Case № IT-98-30/1-A. 28 February 2005.

21. Prosecutor v. Z. Mučič. Case № IT-96-21-T. 16 November 1998.

22. Prosecutor v. M. Milutinovič. Case № IT-05-87-T. 26 February 2009.

23. Prosecutor v. M. Naletillič and V. Martinovič. Case № IT-98-34-T. 31 March 2003.

24. Prosecutor v. E. Ntakirutimana and G. Ntakirutimana. Case № ICTR-96-10-A. 13 December 2004

25. Prosecutor v. G. Rutaganda. Case № ICTR-96-13-T. 6 December 1999.

26. Prosecutor v. M. Stakič. Case № IT-97-24-A. 22 March 2006.

27. Prosecutor v. D. Tadič. Case № IT-94-|-A. 2 October 1995.

28. Prosecutor v. D. Tadic. Case № IT-94-|-T. 7 May 1997.

\section{References}

1. Kibalnik A. G. Kuda idet mezhdunarodnaya ugolovnaya yustitsia? (Where is international criminal justice going?) // Vserossiisky kriminologichesky zhurnal. 2018. Vol. 12. No. 2. P. 300-310. (In Russian)

2. Kibalnik A. G. Ponimanie voennykh prestupleniy $v$ resheniyakh sovremennykh mezhdunarodnykh tribunalov (Understanding of war crimes in the decisions of modern international tribuna/s) // Rossiisky ezhegodnik ugolovnogo prava. No. 7. St. Petersburg: Yuridicheskaya kniga, 2013. P. 439-453. (In Russian)

3. Kibalnik A. G. Prestupleniya protiv chelovechnosti v resheniyakh sovremennykh mezhdunarodnykh sudov (tribunalov) (Crimes against humanity in modern international courts' (tribunals') decisions) // Biblioteka ugolovnogo prava i kriminologii. 2015. No. 4. P. 147-159. (In Russian)

4. Cassese A., Gaeta P., Baig L., Fan M., Gosnell C., Whiting A. Cassese's International Criminal Law. 3rd ed. Oxford University Press, 2013. 414 p.

5. Kittichaisaree K. International Criminal Law. Oxford University Press, 2001. 482 p

6. Prosecutor v. J.-P. Akayesu. Case № ICTR-96-4-T. 2 September 1998.

7. Prosecutor v. Z. Aleksovsky. Case № IT-95-14/1- T. 25 June 1999

8. Prosecutor v. I. Bagilishema. Case № ICTR-95-1A-T. 7 June 2001

9. Prosecutor v. T. Blaškič. Case № IT-95-14-A. 29 July 2004.

10. Prosecutor v. Z. Delalič, Z. Mučič, H. Delič, E. Landzo. Case № IT-96-21-T. 16 November 1998

11. Prosecutor v. S. Gacumbitsi. Case № ICTR-2001-64-T. 17 June 2004

12. Prosecutor v. G. Jelisič. Case № IT-95-10-T. 14 December 1999.

13. Prosecutor v. A. Furundzija. Case № IT-95-17/1-T. 10 December 1998.

14. Prosecutor v. C. Kayishema and O. Ruzindana. Case № ICTR-95-1-T. 21 May 1999

15. Prosecutor v. D. Kordič and M. Čerkez. Case № IT-95-14/2-T. 26 February 2001

16. Prosecutor v. D. Kordič and M. Čerkez. Case № IT-95-14/2-A. 17 December 2004

17. Prosecutor v. R. Krstič. Case № IT-98-33-T. 2 August 2001

18. Prosecutor v. D. Kunarač et al. Case № IT-96-23/23/1-T. 22 February 2001

19. Prosecutor v. D. Kunarač et al. Case № IT-96-23/23/1-A. 12 June 2002.

20. Prosecutor v. M. Kvočka et al. Case № IT-98-30/1-A. 28 February 2005.

21. Prosecutor v. Z. Mučič. Case № IT-96-21-T. 16 November 1998.

22. Prosecutor v. M. Milutinovič. Case № IT-05-87-T. 26 February 2009.

23. Prosecutor v. M. Naletillič and V. Martinovič. Case № IT-98-34-T. 31 March 2003

24. Prosecutor v. E. Ntakirutimana and G. Ntakirutimana. Case № ICTR-96-10-A. 13 December 2004

25. Prosecutor v. G. Rutaganda. Case № ICTR-96-13-T. 6 December 1999.

26. Prosecutor v. M. Stakič. Case № IT-97-24-A. 22 March 2006

27. Prosecutor v. D. Tadič. Case № IT-94-|-A. 2 October 1995.

28. Prosecutor v. D. Tadic. Case № IT-94-|-T. 7 May 1997.

\section{Сведения об авторах}

Невский Руслан Эмильевич - аспирант кафедры уголовного права и процесса Юридического института Северо-Кавказского федерального университета (Ставрополь) / ug_pravo11a@mail.ru

Троицкий Николай Сергеевич - аспирант кафедры уголовного права и процесса Юридического института Северо-Кавказского федерального университета (Ставрополь) / ug_pravo11a@mail.ru

\section{Information about the authors}

Nevsky Ruslan - Postgraduate, Chair of Criminal Law and Criminal Procedure, Law Institute, North Caucasus Federal University (Stavropol) / ug_pravo11a@mail.ru

Troitsky Nikolay - Postgraduate, Chair of Criminal Law and Criminal Procedure, Law Institute, North Caucasus Federal University (Stavropol) / ug_pravo11a@mail.ru 